\title{
Toward a mechanistic understanding of trophic structure: inferences from simulating stable isotope ratios
}

\author{
Kevin J. Flynn ${ }^{1}$ (D) Aditee Mitra ${ }^{1} \cdot$ Antonio Bode $^{2}$
}

Received: 4 October 2017 / Accepted: 14 August 2018 / Published online: 23 August 2018

(c) The Author(s) 2018

\begin{abstract}
Stable isotope ratios (SIR) are widely used to estimate food-web trophic levels (TLs). We built systems dynamic N-biomassbased models of different levels of complexity, containing explicit descriptions of isotope fractionation and of trophic level. The values of $\delta^{15} \mathrm{~N}$ and TLs, as independent and emergent properties, were used to test the potential for the SIR of nutrients, primary producers, consumers, and detritus to align with food-web TLs. Our analysis shows that there is no universal relationship between TL and $\delta^{15} \mathrm{~N}$ that permits a robust prognostic tool for configuration of food webs even if all system components can be reliably analysed. The predictive capability is confounded by prior dietary preference, intra-guild predation and recycling of biomass through detritus. These matters affect the dynamics of both the TLs and SIR. While SIR data alone have poor explanatory power, they would be valuable for validating the construction and functioning of dynamic models. This requires construction of coupled system dynamic models that describe bulk elemental distribution with an explicit description of isotope discriminations within and amongst functional groups and nutrient pools, as used here. Only adequately configured models would be able to explain both the bulk elemental distributions and the SIR data. Such an approach would provide a powerful test of the whole model, integrating changing abiotic and biotic events across time and space.
\end{abstract}

\section{Introduction}

Accurate estimation of the trophic levels (TL) occupied by functional groups or specific organisms is often considered an essential requirement for the determination of the food-web structures. Historically, TLs were assigned through analysis of consumer diet composition (e.g., Pauly et al. 1998; Araujo et al. 2011). However, this approach is confounded by daily changes in diet with resource (prey,

Responsible Editor: C. Harrod.

Reviewed by B. Matthews and an undisclosed expert.

Electronic supplementary material The online version of this article (https://doi.org/10.1007/s00227-018-3405-0) contains supplementary material, which is available to authorized users.

Kevin J. Flynn

k.j.flynn@ swansea.ac.uk

1 Biosciences, Swansea University, Singleton Park, Swansea SA2 8PP, UK

2 Instituto Español de Oceanografía (IEO), Centro Oceanográfico de A Coruña, Apdo. 130, 15080 A Coruña, Spain food) availability, and by difficulties in analysing gut contents (e.g., Cépède 1907; Conway et al. 1998). An alternative method for the determination of TLs makes use of natural abundance stable isotope ratios (SIR) of key elements (e.g., as ${ }^{15} \mathrm{~N} /{ }^{14} \mathrm{~N}$ or, less frequently, ${ }^{13} \mathrm{C} /{ }^{12} \mathrm{C}$ ) (e.g., Boecklen et al. 2011; Layman et al. 2012).

The concept behind the use of SIR is that the TL is reflected by the cumulative isotopic transformations occurring at key biochemical conversions (Cabana and Rasmussen 1996; Robinson 2001; Post 2002; Fry 2006; Jennings et al. 2008). Values of the ratio between heavy and light isotopes of $\mathrm{C}$ or $\mathrm{N}$ within biochemicals or whole organisms are reported as transforms relative to the isotope ratio in a standard using the $\delta$ notation; for $\mathrm{N}$, atmospheric $\mathrm{N}_{2}$ is the standard, being accorded $\delta^{15} \mathrm{~N}=0$. The organismal value of $\delta^{15} \mathrm{~N}$ represents a balance of assimilatory and dissimilatory processes throughout the food chain. The lighter isotope (here, ${ }^{14} \mathrm{~N}$ ) is processed more rapidly; so, primary producers assimilate ${ }^{14} \mathrm{~N}$-nitrate and ${ }^{14} \mathrm{~N}$-ammonium more quickly than they do their ${ }^{15} \mathrm{~N}$-nutrient counterparts, with the organisms becoming isotopically lighter $\left(\delta^{15} \mathrm{~N}\right.$ declines) relative to the source inorganic N. A similar fractionation occurs during ammonium regeneration by consumers, and so they become progressively isotopically heavier ( $\delta^{15} \mathrm{~N}$ increases). 
The cumulative fractionation at each and every biochemical step is ultimately expressed as an emergent property of whole organism isotope fractionation $\left(\Delta^{15} \mathrm{~N}\right)$, with progressive organismal isotopic enrichment up through the consumer chain.

Empirical evidence indicates that isotope composition varies markedly among organisms within different TLs. An average difference in $\delta^{15} \mathrm{~N}$ of $3.4 \%$ o between adjacent TLs has been suggested to be remarkably constant among different types of consumers (Minagawa and Wada 1984; Van der Zanden and Rasmussen 1999, 2001; Post 2002). This has been ascribed to commonality in the net isotopic fractionation in biochemical reactions and physiological processes throughout the food web (Fry 2006). Accordingly, knowledge of the $\delta^{15} \mathrm{~N}$ values of a given consumer and of a reference TL near the base of the food web has been proposed to enable estimation of the consumer TL by applying a constant isotopic enrichment (Cabana and Rasmussen 1996; Post 2002).

The SIR approach fosters an appreciation of the complexity of food webs by providing TL estimations for a variety of consumers (e.g., Bode et al. 2007; Agersted et al. 2014), and how TL may change under different conditions (e.g., Boersma et al. 2016). However, the assumption of a constant enrichment between TLs represents a potential major source of error in the estimations (Caut et al. 2009; Hussey et al. 2014; Jennings and van der Molen 2015). The concept of relating SIR to TL has also been questioned (e.g., Layman et al. 2007 versus Hoeinghaus and Zeug 2008).

Variability around mean isotopic enrichment values between and within different species (Van der Zanden and Rasmussen 2001; McCutchan et al. 2003; Caut et al. 2009; Hussey et al. 2014) are related largely to changes in diet (Dijkstra et al. 2008), and temporal variations in the inorganic $\mathrm{N}$ source for primary producers (Deudero et al. 2004; Bodin et al. 2007; Jennings et al. 2008; Matthews and Mazumder 2005). Consumers feeding upon organisms of lower trophic levels (notably upon herbivores) often display lower isotopic $\mathrm{N}$ enrichment than the average for the food web (Van der Zanden and Rasmussen 1999, 2001; Matthews and Mazumder 2008); the same has been noted for top predators (Hussey et al. 2014), and also for parasites (Pinnegar et al. 2001; Persson et al. 2007). Consumption of detritus, much originating from primary consumers, together with opportunistic omnivory, also affects the low enrichment observed between organisms (e.g., in planktonic systemsRau et al. 1990; Rolff 2000; Bode et al. 2003; Matthews and Mazumder 2008). Further, abiotic stress can affect trophic discrimination in generalist consumers (Reddin et al. 2017). Uncertainties in $\delta^{15} \mathrm{~N}$ at the base of the food web and in trophic fractionations then propagate, causing uncertainty in assignment of TLs (Jennings and van der Molen 2015). The fact remains, however, that SIR provides the only tool that integrates organism activities over a meaningful period of their life span.

Determining the exact TL and SIR over a time course of trophic interactions in nature, as required to rigorously test the relationship between the two, is not possible. The test also needs to be conducted for food webs of different complexity and dynamics. Here, we explore the utility of the SIR approach as a predictor of TL through the use of a system dynamics modelling approach in a way that is not possible empirically. To achieve this, we have taken a dynamic model of a food web operating with a parallel explicit description of isotope discrimination, and compared the SIR signature against the computed real TL over a prolonged simulation period with frequent data sampling. We repeated the analysis using food webs of different levels of complexity. As an exemplar, we used as our study system variants of the widely used N-based marine plankton food web (Fasham et al. 1990). The main food-web model comprised nutrient sources, phytoplanktonic primary producer, four zooplanktonic consumers of increasing size, and also detritus.

\section{Materials and methods}

\section{Model food-web description}

A detailed description of the model is given in electronic supplementary materials (ESM), online. A N-based model was constructed describing a 5-level functional type (FT) planktonic system, where one FT (Phy) was the primary producer (assumed as non-mixotrophic phytoplankton, and hence assigned $\mathrm{TL}=1$ ), together with 4 FTs assigned as consumers (here identified as zooplankton $Z 1$ to Z4). These FTs were interconnected in different ways to provide a series of food webs of increasing complexity (Fig. 1). The activity of all FTs contributed to a common detrital pool; the death rate of Phy increased with deteriorating N-status thus providing phyto-detritus, while $Z 1-Z 4$ contributed to detritus through release of unassimilated (voided) ingestate, as well as via their own death (increasing with deteriorating nutrient status).

Food selection and consumption were described using the approaches of Mitra and Flynn (2006) and Flynn and Mitra (2016), taking into account the likelihood of prey encounter according to allometric constraints linked to motility, consumer and food sizes. Phy was assigned as a motile protist of equivalent spherical diameter (ESD) $10 \mu \mathrm{m}, Z 1$ was assigned as a $50 \mu \mathrm{m}$ ESD protist microzooplankton, while $Z 2-Z 4$ were assigned as mesozooplankton of ESDs 200, 500 and $2000 \mu \mathrm{m}$, respectively. Detritus was considered of similar biomass density as protists, and with a size equating to an ESD of $50 \mu \mathrm{m}$. The model was configured to enable the uppermost consumer, $\mathrm{Z} 4$, to be 

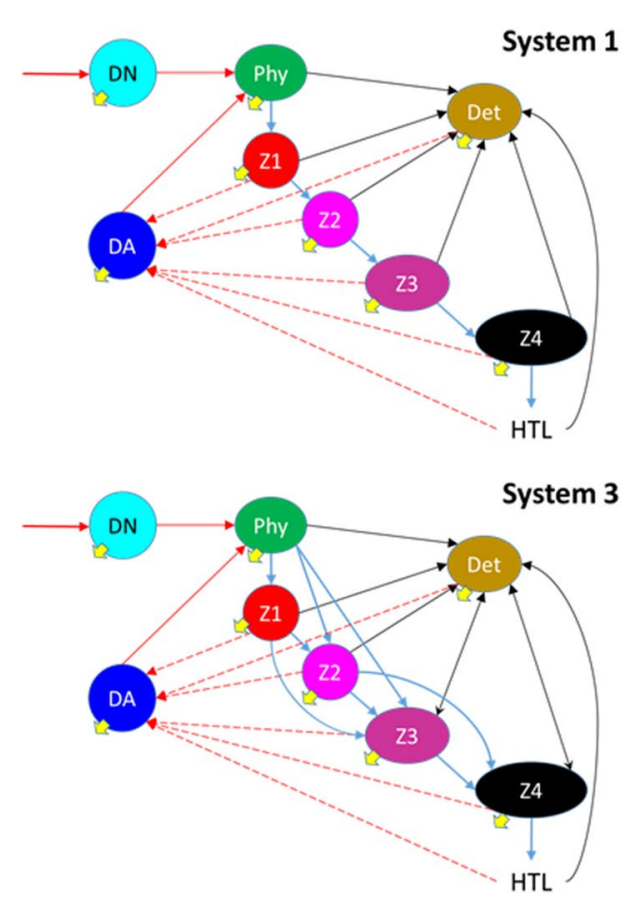

Fig. 1 Food-web structures used in the simulations. Phytoplankton (Phy) uses nitrate (DN) brought into the system and (by priority) ammonium (DA) which is regenerated within it. Nitrate enters the photic zone via mixing (at a rate of $0.05 \mathrm{day}^{-1}$ ) from below the thermocline and the same mixing removes all components (yellow arrows); in essence, the system works akin to a chemostat with nitrate as the only nitrogenous component in the in-flow. All zooplanktonic

grazed by deploying a closure function that represents the activity of higher trophic levels $(H T L)$. In the results shown here, however, it was not necessary to invoke this activity; doing so resulted in the extinction of $\mathrm{Z} 4$ within the $100+$ day simulation period.

Values of constants defining the assimilation efficiency (AE) and maximum growth rates were selected so as to reflect typical literature values for plankton and provide a system that described cycles of trophic dynamics. As any changes in such dynamics affect both the TL status and the distribution of ${ }^{15} \mathrm{~N} /{ }^{14} \mathrm{~N}$ through the same interactions, the exact choice of these values of $\mathrm{AE}$, respiration and growth rates does not affect the general interpretation of our results.

Entry and exit of nutrients and biomass are important factors affecting ecology and also the dynamics of stable isotope distribution. In our modelled planktonic system, entry and exit were described as the process of mixing between the photic and sub-photic zones (set here at a rate of $0.05 \mathrm{day}^{-1}$ ). This mixing introduced new nitrate and removed a fraction of all residual nutrients, biomass and detritus (i.e., described explicitly as total $\mathrm{N}$ and as ${ }^{15} \mathrm{~N}$, and implicitly also ${ }^{14} \mathrm{~N}$ ) from the photic zone.
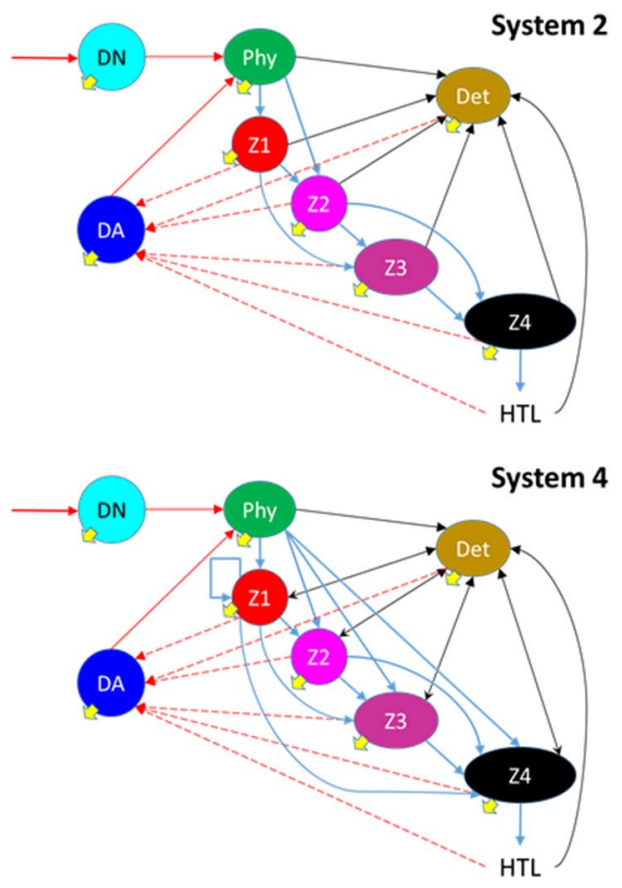

consumers (Z1-Z4) void a proportion of their food, which then contributes to the detritus pool (Det), and also release ammonium. The detritus pool decomposes to contribute to the ammonium pool. $\mathrm{Z} 4$ is also grazed by higher trophic levels (HTL). Note some of the arrows linked to detritus are double-headed, and that Z1 in System 4 can cannibalise. The colours used for the nutrients, organisms and detritus are those used to identify data series in Figs. 2, 3, 4, and 5

\section{Isotope sub-model}

To the description of the fluxes of total $N$ around the food web, we added a parallel model describing the flow of ${ }^{15} \mathrm{~N}$, with differences in $\mathrm{N}$-specific flow rates accounted for by isotope fractionation. Isotopic fractionation is defined by $\alpha$; values of $\alpha>1$ indicate fractionation (typical values of $\alpha$ are ca. 1.005-1.05; Wada and Hattori 1991), while $\alpha=1$ indicates no fractionation. Values of $\alpha$ for different physiological processes were taken as mid-point estimates from Robinson (2001); the exact values of $\alpha$ within the plausible range reported in the literature does not affect the conclusions drawn in our work.

Abiotic mixing process exerted no isotope fractionation but brought in nitrate with $\delta^{15} \mathrm{~N}=5 \%$ (Pantoja et al. 2002). $\mathrm{N}$-source selection by Phy assumed priority consumption of the ammonium regenerated by the consumers; any shortfall in provision of nutrient- $\mathrm{N}$ was then "topped off" by consumption of the nitrate. Values of $\alpha_{\text {nitrate }}$ and $\alpha_{\text {ammonium }}$ were set at 1.009 and 1.015 , respectively.

No isotope fractionation was applied at food selection. Within each consumer, food (prey and/or detritus) was assumed to be processed collectively with the same 
assimilation efficiency (AE; the balance, as 1-AE, being voided) and with no isotopic discrimination. Within the feeding vacuole or gut, the dynamics of assimilation from the digestate were considered akin to a sealed system and hence $\delta^{15} \mathrm{~N}_{\text {digestate }}$ was considered to be the same as $\delta^{15} \mathrm{~N}_{\text {food }}$, with $\alpha_{\text {void }}=1$. In reality, some level of differential assimilation and isotopic discrimination could occur, driven by digestive enzyme activity and metabolite transport across the vacuole membrane or gut wall. This could depend on the duration of digestion set against variable gut transit time (Mitra and Flynn 2007).

Assimilated material may remain within the consumer (contributing to somatic growth) or be respired. Respiration is directly associated with anabolic processes (assimilation and growth with specific dynamic action), and to catabolic respiration (including that associated with homeostasis). Respiration, and the allied regeneration of ammonium, incurs isotope fractionation. Anabolic respiration and regeneration act primarily on the isotopic composition of the incoming digestate, while catabolic respiration and regeneration (especially for $\mathrm{N}$ ) act primarily upon the isotopic composition of the body. Isotopic fractionation of ${ }^{13} \mathrm{C} /{ }^{12} \mathrm{C}$ is affected by such processes through the differential deposition of C in proteins versus lipids (De Niro and Epstein 1977; see also Wolf et al. 2009); this sets the basis of the work by Pecquerie et al. (2010), exploring isotope fractionation via energy flows in consumers. In our model, as $\mathrm{N}$ is primarily apportioned to structural moieties, $\mathrm{N}$ isotope fractionation was applied equally to anabolic and catabolic events, with $\alpha_{\text {regeneration }}=1.006$.

The isotopic signature of the detritus varied as a function of the isotopic composition of the voided material that contributed to it and activities that then degraded it. Release of $\mathrm{N}$ associated with the consumption of Z4 by HTL, as described by the closure term, and with the degradation of detritus, was returned to the inorganic nutrient pool, as ammonium. This process was considered to be complete within the photic zone and accordingly the isotopic composition of the ammonium flux reflected the isotopic content of the source material, with no isotopic fractionation.

\section{Trophic level sub-model}

TLs were not apportioned through reference to the web structures shown in Fig. 1; the value of the TL for each FT was computed through reference to the dynamics of $\mathrm{N}$ flowing through the biotic system. While Phy was confined to $\mathrm{TL}=1$, the status of the other components $(Z 1, Z 2, Z 3, Z 4$, detritus) each changed as a function of their prior TL, and with the TL status of the incoming contributing nitrogenous material.

A special instance in allocation of the TL was that for the detrital pool. The importance of the detrital pool and activities of its components in ecology is often understated (Moore et al. 2004), or "invisible" (Gutiérrez-Rodríguez et al. 2014), with the exact origins of the material (including allochthonous sources) causing additional challenges in SIR interpretation (Mallela and Harrod 2008; Nilsen et al. 2008; Docmac et al. 2017). In reality, a proportion of what is in the modelled detrital material would be microbial detritivores. To fully describe this material would require explicit description of the microbial consortia and of their activities; this was considered to be beyond the needs of the current work. While the TL status of detrital material including any allied microbes would be higher than indicated here, as both the calculated TL and $\delta^{15} \mathrm{~N}$ values were subjected to the same assumptions, the validity of our test is maintained.

\section{Simulations}

We present the results from explorations of four food-web configurations (Fig. 1), with increasing levels of complexity from a simple linear food chain (System 1) to the most complex (System 4), in which each consumer could feed on detritus and on primary producers, and $Z 1$ (here considered as a protist microzooplankton) could also cannibalise. Simulations were run at three input nitrate concentrations. Values of $\delta^{15} \mathrm{~N}$ for different components are reported using the syntax $\delta^{15} \mathrm{~N}_{\text {component }}$.

Understanding the dynamics of $\delta^{15} \mathrm{~N}$ is complicated by the combination of dilution and discrimination events operating over the time prior to sampling (Robinson 2001; Phillips et al. 2014). Models also require a period of spin-up to establish the values of state variables for TL and $\delta^{15} \mathrm{~N}$. Accordingly, sampling the simulation data was commenced 20 or more days after the start of simulations.

\section{Results}

Figures 2, 3, 4, 5 and 6 show results for the mid-level nitrate input $(20 \mu \mathrm{M})$, while summary statistics for all systems and nitrate inputs are shown in Table 1.

Figure 2 shows the functioning of the simplest system, as a linear food chain (Fig. 1, System 1). In the presence of sufficient nitrate, the discrimination at $\mathrm{N}$-source assimilation during initial primary production gives a strongly negative $\delta^{15} \mathrm{~N}_{\text {Phy }}$. During bloom development, as $\mathrm{N}$ sources become limiting, both the residual nutrients $\left(\delta^{15} \mathrm{~N}\right)$ and $\delta^{15} \mathrm{~N}_{\text {Phy }}$ become increasingly positive. At the peak of the blooms, as almost all ${ }^{14} \mathrm{~N}$ and ${ }^{15} \mathrm{~N}$ nitrate becomes assimilated into Phy, $\delta{ }^{15} \mathrm{~N}_{\text {Phy }}$ becomes similar to that of the incoming nitrate $\left(\delta^{15} \mathrm{~N}_{\text {nitrate }}=5 \%\right.$ ). These transients in $\delta^{15} \mathrm{~N}_{\text {Phy }}$ feed into the consumer chain and, although the trophic levels (TL) remain constant for each functional type in this simple linear food chain (except for detritus), the value of $\delta^{15} \mathrm{~N}$ for each 
Fig. 2 Time plots of the partitioning of $\mathrm{N}$ in System 1 between dissolved nitrate (DN; cyan), ammonium (DA; blue), phytoplankton (Phy; green), four zooplankton functional types (Z1-Z4; red, pink, dark pink and black, respectively) and detritus (brown). Other time plots show the values of $\delta^{15} \mathrm{~N}$ and trophic level (TL) of the biotic components. See Fig. 1 for details of the food web structure. The relationship between TL and $\delta^{15} \mathrm{~N}$ is shown for each functional group; the slope of the relationship is given in Table 1 as the "midN" value
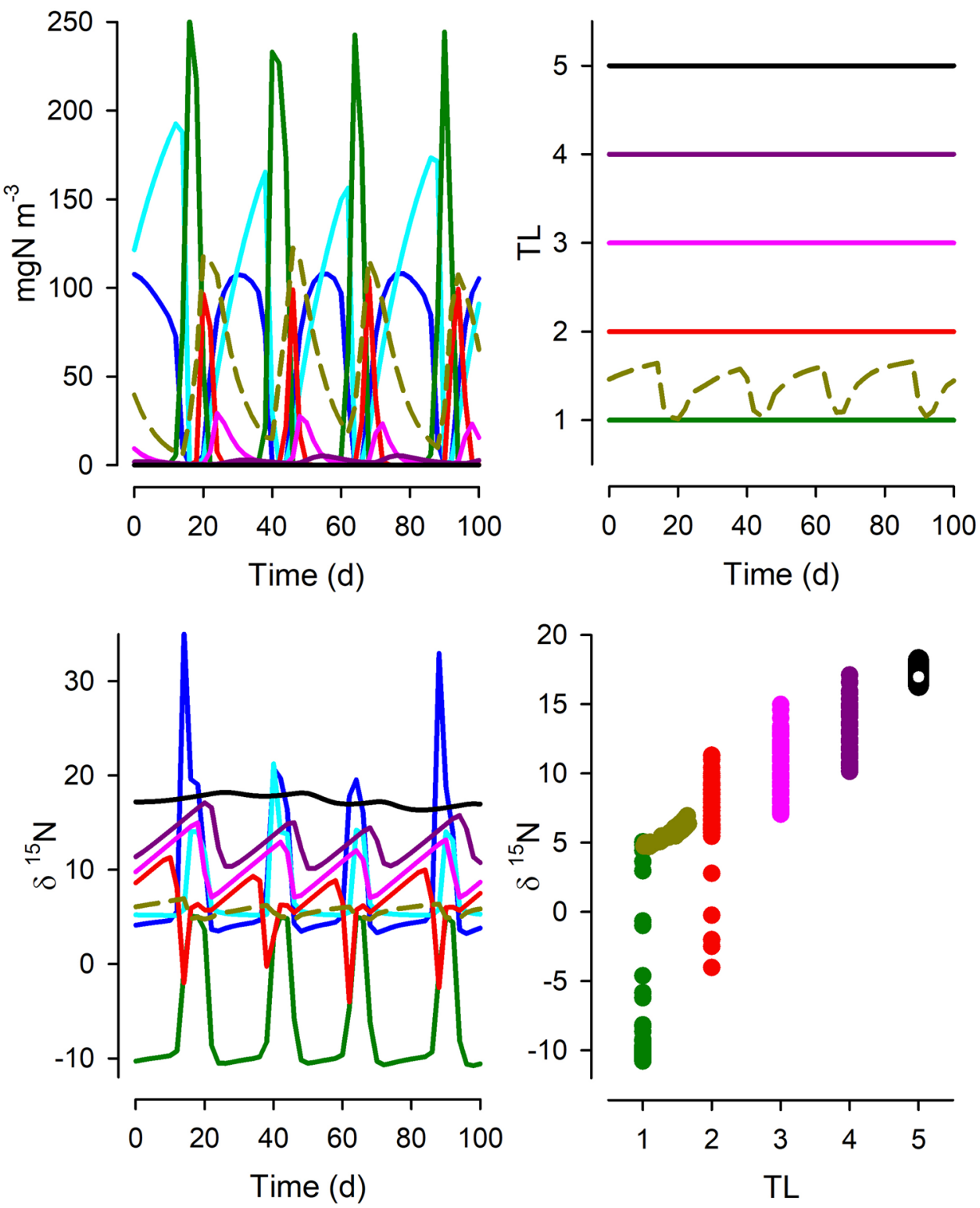

component varies greatly with the cycles of predator-prey dynamics. In consequence, the relationship between TL and $\delta^{15} \mathrm{~N}$ shows considerable spread. Table 1 shows that the slope of the relationship, either with reference to all biomass groups, excluding phytoplankton, or excluding phytoplankton and also detritus. Even for this simplest of systems, the slope of the relationship in the simulation output is not constant, though the value of $R^{2}$ is high. Further, the slope varies as a function of the resource abundance (altered here by lower and higher nitrate input levels, noting that these concentrations affect consumer abundance and thence also predator-prey activities); the slope of TL vs $\delta^{15} \mathrm{~N}$ was higher when the system operated at higher resource abundance.

System 2 differs from System 1 by having additional predator-prey interactions (Fig. 1). The dynamics are very different (Fig. 3, cf. Figure 2), and the trophic level of individual consumer types now varies over the simulation period. The relationship between TL and $\delta^{15} \mathrm{~N}$ is poorer than for System 1 and the slopes are notably lower (Table 1). System 3 sees additional food-web complexity, including now an ability by Z3 and Z4 to consume material from the detrital pool (Fig. 1). In this system, Z2 and Z3 become minor components, so that $\mathrm{Z} 4$ de facto acquires a much lower $\mathrm{TL}$ than may be expected from the web construction (Fig. 4). The relationship between TL and $\delta^{15} \mathrm{~N}$ differs further from those for Systems 1 and 2 (Table 1), again with the "All" data relationship returning a higher TL vs $\delta{ }^{15} \mathrm{~N}$ slope from high-resourced systems.

System 4 is the most complex food web, including cannibalism (intraguild predation) within $Z 1$, with a wider range of food options and all zooplankton capable of consuming detrital material (Fig. 1). Here, the TL of each plankton FT 
Fig. 3 As Fig. 2 but for System 2; see legend of Fig. 2 for an explanation of line and symbol types. See also Fig. 1 and Table 1
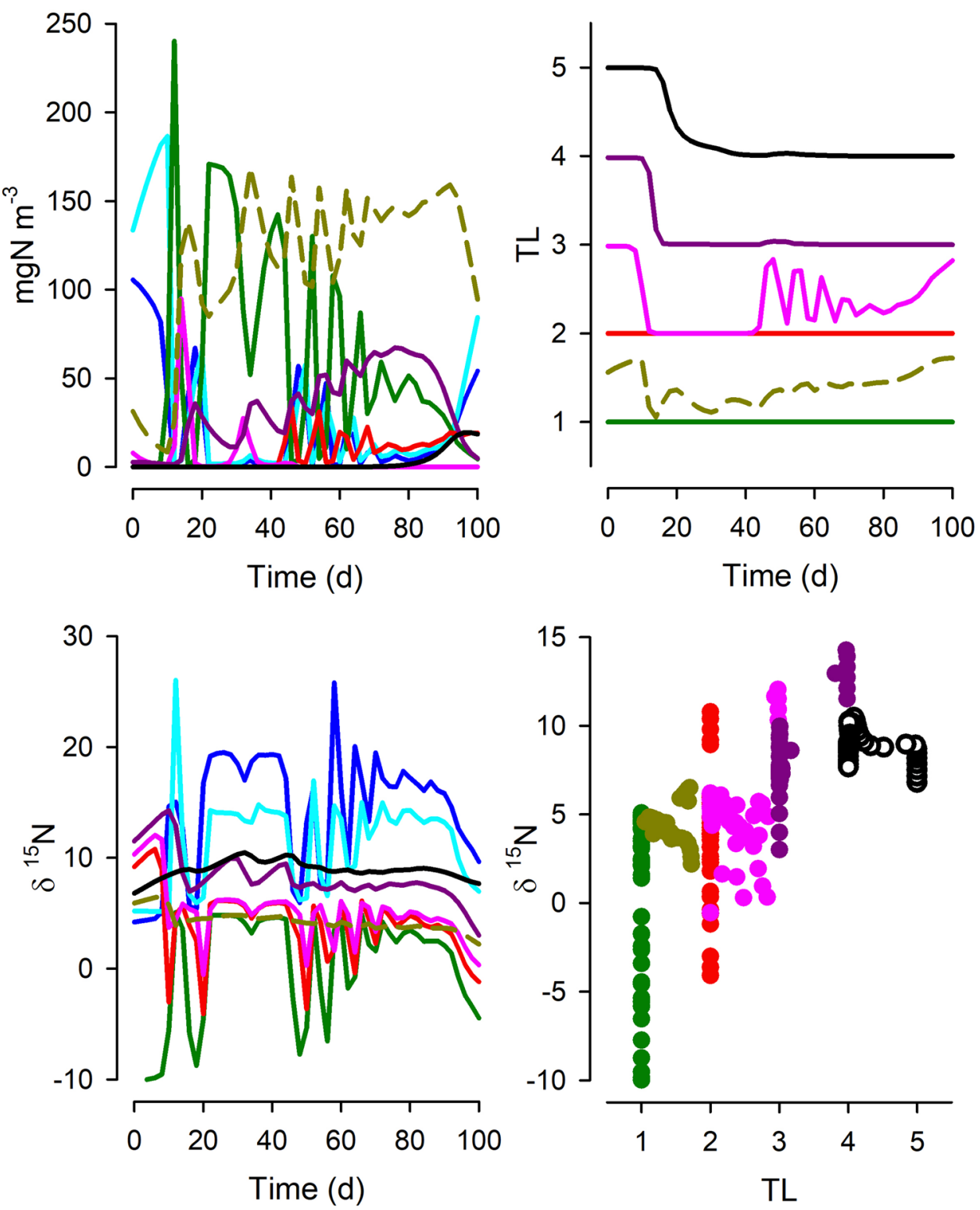

changes greatly over the food-web cycles (Fig. 5), and over time the TLs also increase due to the combined effects of cannibalism and recycling of detrital material. Despite this, the relationship between TL and $\delta^{15} \mathrm{~N}$ is in keeping with those seen in the other simulations, though again varying depending on the resource abundance (Table 1).

Figure 6 shows the relationship between TL and $\delta^{15} \mathrm{~N}$ from samples taken, at 20-day intervals after the initial spinup period, from all systems run at the mid-nitrate abundance (as per Figs. 2, 3, 4, 5). Table 1 gives the slopes of the relationship across all of these systems, showing (as with the systems considered individually) a steeper slope when all functional types ( $P h y, Z 1 \ldots Z 4$ and detritus) are included, less steep when only the consumers $(Z 1 \ldots Z 4)$ are considered, and a lower slope again when considering consumers plus detritus excluding just the phytoplankton.

\section{Discussion}

The purpose of establishing the trophic level (TL) of different groups of organisms is to aid the understanding of ecological linkages, supporting the construction of conceptual and thence computational descriptions of food webs. The use of changes in values of $\delta^{15} \mathrm{~N}$ and $\delta^{13} \mathrm{C}$, in theory, provides a method to determine trophic activity integrated over time and space. There are, however, clear challenges in decoding stable isotope signatures in field and also laboratory microcosms (Farquhar et al. 1989; Flynn and Davidson 1993; Auerswald et al. 2010; Layman et al. 2012), many of which centre around issues of isotope discrimination at different biochemical and trophic levels, of isotope cycling and dilution (Robinson 2001). While alternate nitrogen pathways may be indicated by consumer $\delta^{15} \mathrm{~N}$ time series 
Fig. 4 As Fig. 2 but for System 3 ; see legend of Fig. 2 for an explanation of line and symbol types. See also Fig. 1 and Table 1
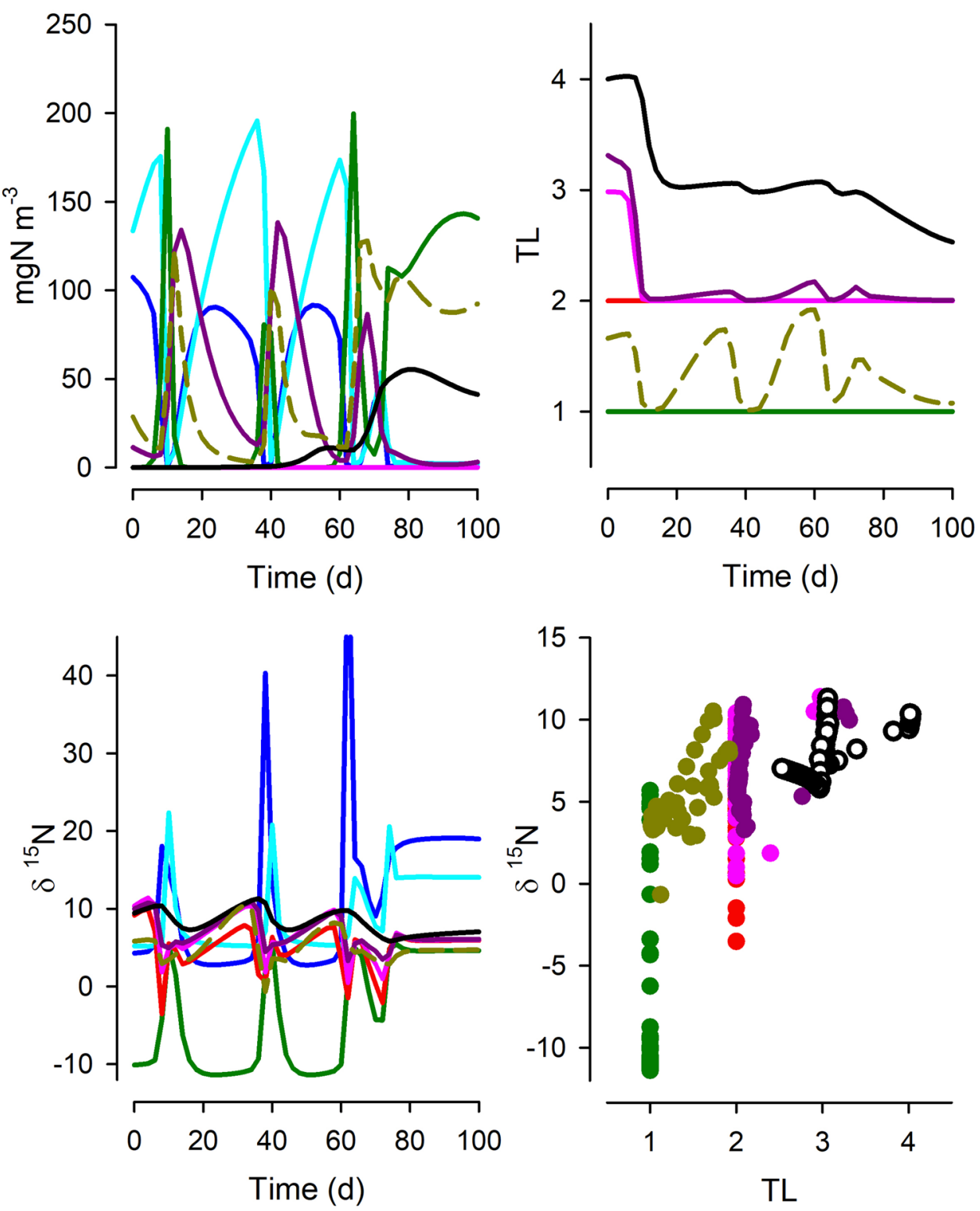

data (Matthews and Mazumder 2007), multiple system components need to be examined to assess trophic structure in complex food webs. Phillips et al. (2014) give recommendations on modelling approaches exploiting SIR data, stressing the importance of suitable spatial-temporal and organism sampling strategies. Though easier to follow for some food webs than for others, these recommendations are invariably challenging. Field sampling is typically extremely patchy in time and space, and especially for microbial systems (e.g., plankton) simply separating different functional groups for analysis can be very difficult.

What our work shows is that even in the utopian situation of having a full data set from a well-studied system, we cannot expect a simple robust relationship between $\delta^{15} \mathrm{~N}$ and TL. The same food-web structure, but just operating under different nutrient loads, is seen to exhibit different relationships. This is demonstrated by the variation in TL vs $\delta{ }^{15} \mathrm{~N}$ slope values when we simulated the food webs under different resource availabilities (Table 1). The totality of the complexity of unravelling isotope discrimination relative to TL is additionally demonstrated by Figs. 2, 3, 4, 5 and 6. While we may be able to explain changes in $\delta^{15} \mathrm{~N}$ through reference to our understanding of ecophysiology and ecology, the converse (using $\delta^{15} \mathrm{~N}$ as an explanatory tool) appears challenging even if we have an ideal series of SIR data.

\section{The failure of SIR to describe TLS}

Models exploiting field data typically access SIR values at very few time points, and, thus, attempt to rebuild trophic dynamics from SIR values that are themselves affected by 
Fig. 5 As Fig. 2 but for System 4; see legend of Fig. 2 for an explanation of line and symbol types. See also Fig. 1 and Table 1
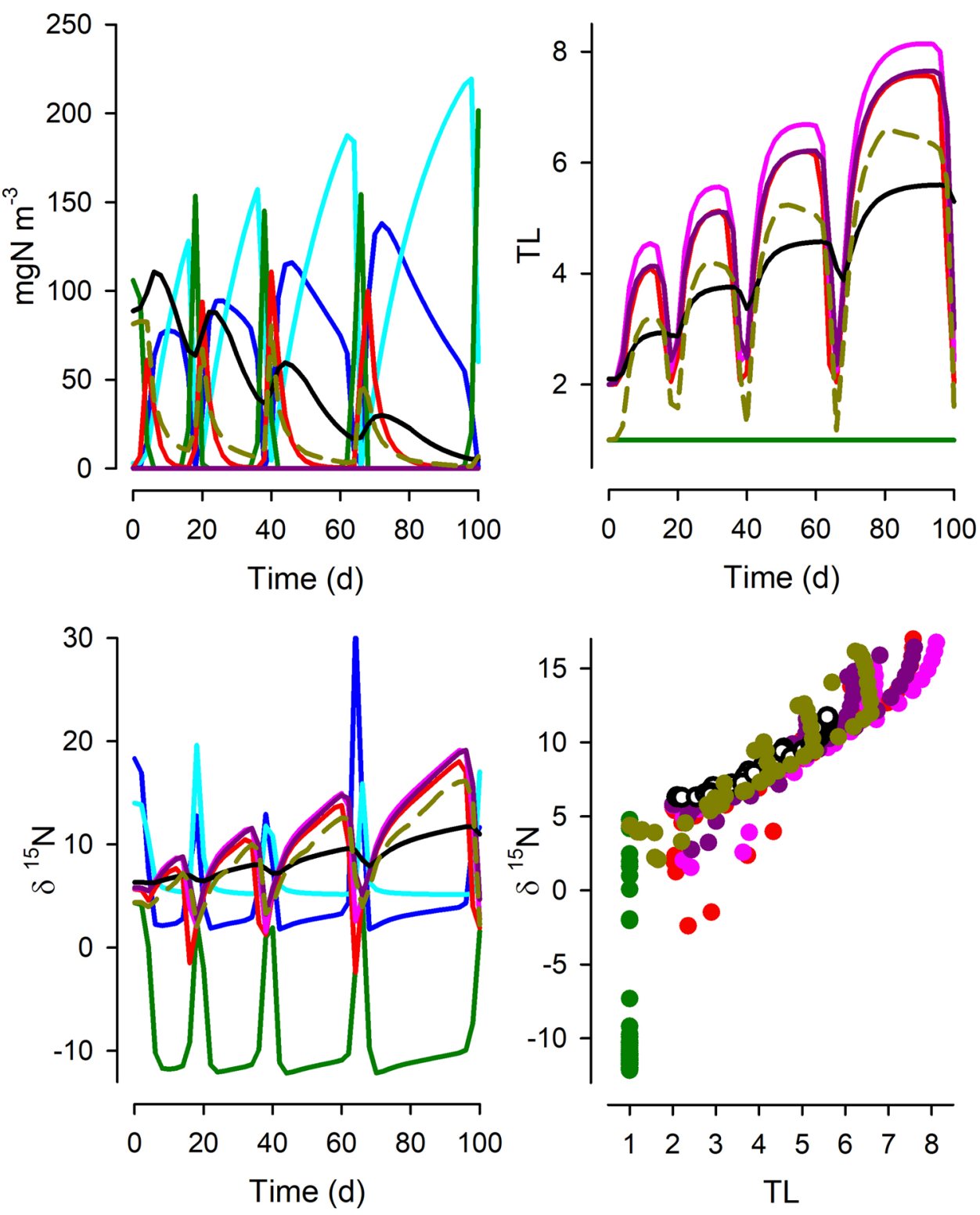

many, un-sampled, dynamic processes. Different modelling strategies have tried to make sense of the relationship between TL and $\delta^{15} \mathrm{~N}$; Middelburg (2014) gives an overview of methods used to make inferences about trophic structure from SIR. Models in this context include simple statistical approaches, through to Bayesian approaches and simulations (Parnell et al. 2010, 2013; Kadoya et al. 2012; Van Engeland et al. 2012; Brett et al. 2016; Yeakel et al. 2016). Inverse modelling approaches have also been proposed (Eldridge et al. 2005; Van Oevelen et al. 2010), to de facto rebuild the most likely trophic system that could explain the SIR data. Our approach contrasts with other modelling attempts to explore the relationship between SIR and TL, through explicitly modelling the flow of ${ }^{15} \mathrm{~N}$, involving biochemical fractionation rather than implicit or assumed organismal fractionation, and also by calculating TLs.
A key challenge in this arena is that the relationship between TL and $\delta^{15} \mathrm{~N}$ is dynamic and, because of various factors, each of these variables changes out of sequence with each other. Indeed, the timing sequence itself varies with the dynamics of the physiology and interconnectivity of the organisms, which is in turn affected by resource (nutrient, food, prey) availability. The dynamics are affected by the nutrient loading because high loading raises biomass levels and hence encounter rates, and allied predator-prey interactions change. Olive et al. (2003) specifically explored the dynamics of SIR change during diet switching making use of a linear model; this dynamic is portrayed in our model not only with respect to diet switching at one level, but with the subsequent cascade of SIR values (and changes in TL) through other parts of the trophic web. When considering isotope discrimination, there is an additional aspect related 


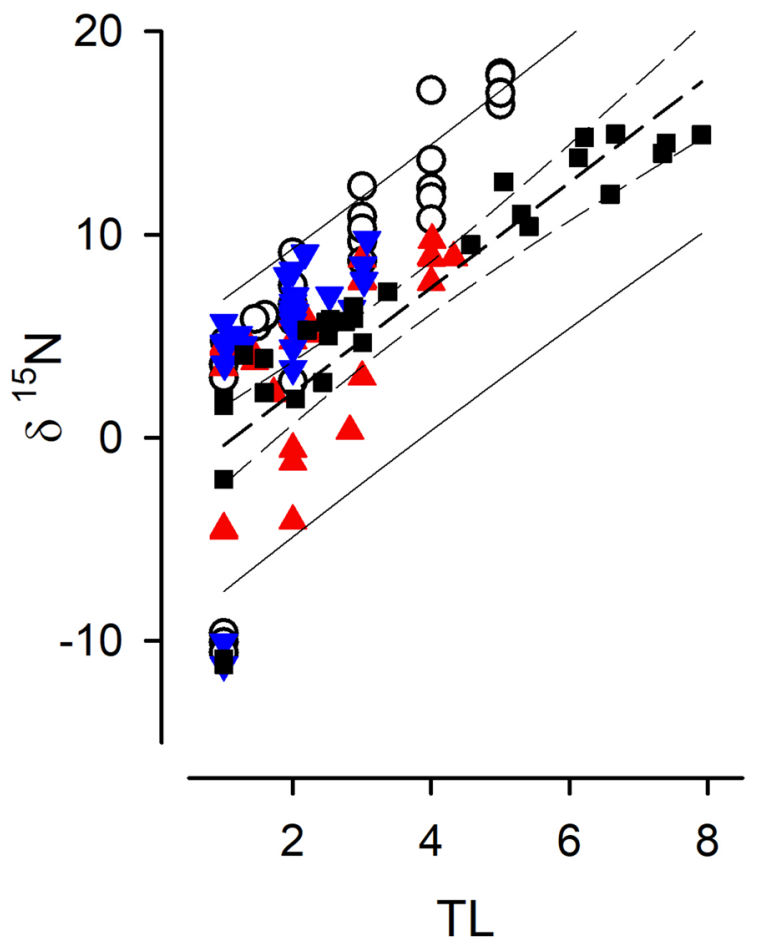

Fig. 6 The relationship between TL and $\delta^{15} \mathrm{~N}$ for data taken every 20 days from the simulations shown in Figs. 2, 3, 4 and 5. System 1-open circles; System 2-red triangles; System 3-blue inverted triangles; System 4-black squares. See also Table 1. The dark dashed line is the line of best fit (linear regression) through all the plotted data, the thin dashed lines are the $95 \%$ confidence limits for that best fit, and the thin continuous lines are the $95 \%$ predictive limits (computed by SigmaPlot 12.5, Systat Software Inc)

to nutrient loading, and that concerns the availability of ${ }^{14} \mathrm{~N}$ vs ${ }^{15} \mathrm{~N}$ in nitrate and ammonium, which then affects $\delta^{15} \mathrm{~N}$ of the phytoplankton (e.g., see Fig. 2).

From our simulations, it can be seen that there is no universal relationship between TL and $\delta^{15} \mathrm{~N}$ that permits a robust prognostic tool for configuration of food webs even if all system components can be reliably analysed. Thus, the slopes of the relationship between TL vs $\delta^{15} \mathrm{~N}$ vary greatly between systems of different complexity and temporal dynamics and nutrient load (Table 1). This conclusion conflicts with suggestions that difference in $\delta^{15} \mathrm{~N}$ of ca. 3.4\% aligns with a difference of 1 trophic level (Van der Zanden and Rasmussen 2001). A consideration of a more dispersed sampling regime (Fig. 6), rather than tightly sequential sampling regime in systems of known history (Figs. 2, 3, 4,5 ), also shows not only the spread in the slope but also the problem of establishing the intercept of the relationship. This affects the ability to determine the TL from a given SIR, as finding an appropriate baseline to make ecological inferences is far from trivial (Cabana and Rasmussen 1996; Post 2002; Matthews and Mazumder 2005); in nature the "baseline" can never be truly fixed.
An alternative approach to assuming a fixed TL- $\delta^{15} \mathrm{~N}$ relationship is the development of empirical relationships to account for the decrease in $\delta^{15} \mathrm{~N}$ enrichment up the food webs, as shown through meta-analysis of previous data for top marine predators (Hussey et al. 2014). In that way, the resulting food web structures have more TLs than would be estimated by traditional whole-ecosystem models based on constant ${ }^{15} \mathrm{~N}$ enrichment. The technique we deploy here could be used to check the power of such ideas from a conceptual basis. In our work, with the same number of functional groups though connected differently, 5 operational TLs emerge within System 1 (Fig. 2), while emergent TLs within System 4 exceeded 8 (Fig. 5). Furthermore, in System 4, where the protist $Z 1$ could be cannibalistic, the TL for $Z 1$ could exceed that for the mesozooplankton $Z 4$; this reflects a series of predator-prey interactions within a functional grouping depending on the role of intraguild cannibalism and of detritivory. Thus, the colloquial interpretation of trophic levels (e.g., that larger metazoan have a higher TL than do micrograzers) can be seen to be challenged in food webs with a high level of dynamic complexity. The upward spiral in TL (Fig. 5) was matched by changes in $\delta^{15} \mathrm{~N}$ such that the slope of the TL vs $\delta^{15} \mathrm{~N}$ relationship was not dissimilar for System 4 as for other systems (Table 1).

The results of our simulations also help to explain the findings in field studies that show an uneven propagation of the $\delta^{15} \mathrm{~N}$ through the food web (Bode et al. 2007; Jennings et al. 2008; Mompeán et al. 2013). Changes in the temporal variation in $\delta^{15} \mathrm{~N}$ have been attributed primarily to body-size effects affecting the turnover of body tissues, as such changes are significantly greater in smaller animals (assumed of lower TL and higher specific growth rates) and decline continuously with body size (Jennings et al. 2008; Reum et al. 2015). Empirical studies also point to a key role of plankton size in determining the number of TLs (Hunt et al. 2015).

The effects of deploying different values of $\alpha$ at different stages can also be explored using the type of approach we used. Thus, the changing relationship between $\delta^{15} \mathrm{~N}$ enrichment with organism size may relate to differences in discrimination at assimilatory (digestion and anabolism) versus dissimilatory (catabolic) processes relating to structure and biochemical/physiological differences between consumers, their rate and frequency of feeding, and their net growth rate. In our simulations, we set no discrimination at assimilation $\left(\alpha_{\text {void }}=1\right)$, but alternative configurations could be readily explored.

\section{An alternative use for SIR data}

Despite all efforts to provide a robust diagnostic tool for food-web studies using SIR (e.g., Layman et al. 2012; Jennings and van der Molen 2015), the combined complexities 
Table 1 Relationship between trophic level (TL) and $\delta^{15} \mathrm{~N}$ for simulations run within food webs of different complexity (see Fig. 1)

\begin{tabular}{|c|c|c|c|c|c|c|c|}
\hline \multirow[t]{2}{*}{ Data sampled } & \multirow[t]{2}{*}{ System } & \multicolumn{2}{|l|}{ loN } & \multicolumn{2}{|l|}{$\operatorname{midN}$} & \multicolumn{2}{|l|}{ hiN } \\
\hline & & Slope & $R^{2}$ & Slope & $R^{2}$ & Slope & $R^{2}$ \\
\hline \multirow[t]{5}{*}{ All } & 1 & 2.68 & 0.90 & 4.72 & 0.70 & 6.61 & 0.76 \\
\hline & 2 & 2.03 & 0.70 & 2.50 & 0.45 & 3.76 & 0.48 \\
\hline & 3 & 1.97 & 0.35 & 4.61 & 0.38 & 7.51 & 0.46 \\
\hline & 4 & 2.30 & 0.41 & 3.28 & 0.77 & 3.05 & 0.36 \\
\hline & All & & & 2.78 & 0.53 & & \\
\hline \multirow[t]{5}{*}{ All except Phy } & 1 & 2.79 & 0.91 & 3.24 & 0.83 & 5.28 & 0.78 \\
\hline & 2 & 1.96 & 0.72 & 1.95 & 0.44 & 2.57 & 0.47 \\
\hline & 3 & 1.75 & 0.29 & 2.18 & 0.30 & 2.11 & 0.10 \\
\hline & 4 & 1.56 & 0.50 & 2.14 & 0.86 & 1.30 & 0.22 \\
\hline & All & & & 2.16 & 0.61 & & \\
\hline \multirow[t]{5}{*}{ All except Phy \& detritus } & 1 & 3.03 & 0.91 & 3.48 & 0.77 & 5.45 & 0.68 \\
\hline & 2 & 2.03 & 0.64 & 2.21 & 0.41 & 2.46 & 0.35 \\
\hline & 3 & 1.59 & 0.16 & 2.39 & 0.25 & 1.18 & 0.03 \\
\hline & 4 & 1.47 & 0.44 & 2.19 & 0.87 & 1.23 & 0.19 \\
\hline & All & & & 2.30 & 0.57 & & \\
\hline
\end{tabular}

These relationships considered model outputs taken every 2 days over a 100 day period following a spinup period of at least 20 days. The data shown in Figs. 2, 3, 4, 5 and 6 were from systems supplied with $20 \mu \mathrm{M}$ nitrate, labelled "midN" here. Simulations were also run at $10 \mu \mathrm{M}$ nitrate ("loN") and $40 \mu \mathrm{M}$ nitrate ("hiN"). Also, shown are the relationships for the entire data series shown in Fig. 6 (system "all"; "midN" only). The relationship (slope) was calculated either with inclusion of all organisms and detritus ("All"), excluding the phytoplankton data ("All except Phy"), or excluding phytoplankton and detritus ("All except Phy \& detritus"; i.e., only considering consumers Z1.. Z4). These slopes may be compared to the proposed expected value of $\delta^{15} \mathrm{~N}=3.4 \%$ per TL (Minagawa and Wada 1984; Van der Zanden and Rasmussen 1999, 2001; Post 2002) of the trophic dynamics, isotope discrimination and dilution appear to confound such usage. The rate at which the SIR in a given consumer approaches equilibrium is a function of the stability of the SIR in the diet and of the metabolic rate of the consumer (Woodland et al. 2012), a set of interactions that is repeated at each organism, and interacts throughout the ecosystem, as demonstrated in our simulations. It seems most likely that using SIR of specific biochemical markers (Brett et al. 2016) will be fraught with similar problems due to different levels of isotope discrimination at internal localised assimilatory and dissimilatory pathways.

Returning to the original purpose of why one wishes to know the TL, and how SIR signatures could aid in such determinations (i.e., integrating over temporal and spatial activities), it becomes apparent from our work that the ability of a dynamic ecosystem model to describe the SIR data through an explicit description of isotope fractionation dynamics, could itself provide a useful validation tool for systems ecology. This potential becomes even more powerful when considering the impacts of physical processes on the temporal and spatial distribution of nutrients and biotic components (here, as nitrate, plankton and detritus). This approach could offer a valuable addition to ecological science because obtaining validation data for modelling is a serious impediment to research; data are typically so sparse that all too often they are consumed in model testing and configuration, leaving few or none for model validation. If the bulk elemental data were used for optimising the model, then the concurrently collected SIR data could be used for validation. Simultaneously, the approach also tests what we know of organism physiology, decay processes, food quality and quantity relationships, and how we describe all of these within simulation models.

While several researchers (e.g., Nilsen et al. 2008; Van der Lingen and Miller 2011; Deehr et al. 2014) have attempted calibrations of Ecopath models through reference to SIR, that is a rather different approach compared to using SIR data for validation of a dynamic model that is built with (totally coupled to) an explicit dynamic isotope description. Likewise, the use of biovolume spectrum-based analyses to compare with SIR estimates of TL (Basedow et al. 2016) differs in that there is no independent measure of TL.

A systems dynamic simulation, as we used here, does not actually rely on values of TL at all; rather the value of TL is an emergent feature of the functioning of the ecosystem, which is as it should be. Likewise, the organism $\delta^{15} \mathrm{~N}$ and whole organism isotope fractionation $\left(\Delta^{15} \mathrm{~N}\right)$ are also emergent features, stemming from isotope discrimination at key physiological events within each organism functional type. Our work acts as a proof of concept for suggestions that 
more closely coupled experiments and simulations would help to disentangle isotopic routing of specific molecules and their influence on $\delta^{15} \mathrm{~N}$ (and TL) of whole organisms (McCarthy et al. 2007; Wolf et al. 2009).

\section{Conclusion}

Our analysis of SIR signatures vs TLs, and the modelling of them, emphasises that constructing food webs is not simply a matter of connectivity; the dynamics inherent within those connections (including facets of the physiology of the organisms; Dijkstra et al. 2008) are critical. Interactions between these components, the functioning of the abiotic system in which the ecology operates, and changes in those dynamics over the life cycle of organisms collectively explain why SIR cannot robustly describe TLs. Dynamic modelling of organismal elemental and isotope content together, with validation against SIR signatures, offers a powerful unifying approach in ecological research. Only models that are of adequate construction will be able to satisfactorily explain the SIR data. The platform could also be used to generate data series for testing other approaches, such as Bayesian inverse and mixing models.

Acknowledgements We thank Jack Middelburg, and several anonymous referees for their valuable comments on earlier versions of this work.

Author contributions KJF and AM conceived, built and ran the model with guidance from $\mathrm{AB}$. All authors contributed to analysis of the results and writing of the paper.

Funding This research was supported by project EUROBASIN (EU FP7 Project no. 246933), and by the Natural Environment Research Council (NERC, UK) through its iMARNET programme.

\section{Compliance with ethical standards}

Conflict of interest Author Flynn declares that he has no conflict of interest. Author Mitra declares that she has no conflict of interest. Author Bode declares that he has no conflict of interest.

Human or animal rights This article does not contain any studies with animals performed by any of the authors.

Open Access This article is distributed under the terms of the Creative Commons Attribution 4.0 International License (http://creativeco mmons.org/licenses/by/4.0/), which permits unrestricted use, distribution, and reproduction in any medium, provided you give appropriate credit to the original author(s) and the source, provide a link to the Creative Commons license, and indicate if changes were made.

\section{References}

Agersted MD, Bode A, Nielsen TG (2014) Trophic position of coexisting krill species: a stable isotope approach. Mar Ecol Prog Ser 516:136-151

Araujo MS, Bolnick DL, Layman CA (2011) The ecological causes of individual specialisation. Ecol Lett 14:948-958

Auerswald K, Wittmer MHOM, Zazzo A, Schaufele R, Schnyder H (2010) Biases in the analysis of stable isotope discrimination in food webs. J Appl Ecol 47:936-941

Basedow SL, de Silva NAL, Bode A, van Beusekorn J (2016) Trophic positions of mesozooplankton across the North Atlantic: estimates derived from biovolume spectrum theories and stable isotope analyses. J Plankton Res 38:1364-1378

Bode A, Carrera P, Lens S (2003) The pelagic foodweb in the upwelling ecosystem of Galicia (NW Spain) during spring: natural abundance of stable carbon and nitrogen isotopes. ICES J Mar Sci 60:11-22

Bode A, Alvarez-Ossorio MT, Cunha ME, Garrido S, Peleteiro JB, Porteiro C, Valdés L, Varela M (2007) Stable nitrogen isotope studies of the pelagic food web on the Atlantic shelf of the Iberian Peninsula. Prog Oceanogr 74:115-131

Bodin N, Le Loc'h F, Hily C, Caisey X, Latrouite D, Le Guellec AM (2007) Variability of stable isotope signatures $\left(\delta^{13} \mathrm{C}\right.$ and $\left.\delta^{15} \mathrm{~N}\right)$ in two spider crab populations (Maja brachydactyla) in Western Europe. J Exp Mar Biol Ecol 343:149-157

Boecklen WJ, Yarnes CT, Cook BA, James AC (2011) On the use of stable isotopes in trophic ecology. Annu Rev Ecol Evol Syst 42:411-440

Boersma M, Mathew KA, Niehoff B, Schoo KL, Franco-Santos RM, Meunier CL (2016) Temperature driven changes in the diet preference of omnivorous copepods: no more meat when it's hot? Ecol Lett 19:45-53

Brett M, Eisenlord M, Galloway A (2016) Using multiple tracers and directly accounting for trophic modification improves dietary mixing-model performance. Ecosphere 7:e01440. https://doi. org/10.1002/ecs 2.1440

Cabana G, Rasmussen JB (1996) Comparison of aquatic food chains using nitrogen isotopes. Proc Natl Acad Sci 93:10844-10847

Caut S, Angulo E, Courchamp F (2009) Variation in discrimination factors $\left(\Delta^{15} \mathrm{~N}\right.$ and $\left.\Delta^{13} \mathrm{C}\right)$ : the effect of diet isotopic values and applications for diet reconstruction. J Appl Ecol 46:443-453

Cépède C (1907) Contribution à l'étude de la nourriture de la sardine. C R Acad Sci 144:770-772

Conway DVP, Coombs SH, Smith C (1998) Feeding of anchovy Engraulis encrasicolus larvae in the northwestern Adriatic Sea in response to changing hydrobiological conditions. Mar Ecol Prog Ser 175:35-49

De Niro MJ, Epstein S (1977) Mechanism of carbon isotope fractionation associated with lipid synthesis. Science 197:261-263

Deehr RA, Luczkovich JJ, Hart KJ, Clough LM, Johnson BJ, Johnson JC (2014) Using stable isotope analysis to validate effective trophic levels from Ecopath models of areas closed and open to shrimp trawling in Core Sound, NC, USA. Ecol Model 282:1-17

Deudero S, Pinnegar JK, Polunin NVC, Morey G, Morales-Nin B (2004) Spatial variation and ontogenic shifts in the isotopic composition of Mediterranean littoral fishes. Mar Biol 145:971-981

Dijkstra P, LaViolette CM, Coyle JS, Doucett RR, Schwartz E, Hart $\mathrm{SC}$, Hungate BA $(2008){ }^{15} \mathrm{~N}$ enrichment as an integrator of the effects of $\mathrm{C}$ and $\mathrm{N}$ on microbial metabolism and ecosystem function. Ecol Lett 11:389-397

Docmac F, Araya M, Hinojosa DL, Dorador C, Harrod C (2017) Habitat coupling writ large: pelagic-derived materials fuel 
benthivorous macroalgal reef fishes in an upwelling zone. Ecology 98:2267-2272

Eldridge PM, Cifuentes LA, Kaldy JE (2005) Development of a stable-isotope constraint system for estuarine food-web models. Mar Ecol Prog Ser 303:73-90

Farquhar GD, Ehleringer JR, Hubick KT (1989) Carbon isotope discrimination and photosynthesis. Annu Rev Plant Physiol Plant Mol Biol 40:503-537

Fasham MJR, Ducklow HW, Mckelvie SM (1990) A nitrogen-based model of plankton dynamics in the oceanic mixed layer. J Mar Res 48:591-639

Flynn KJ, Davidson K (1993) Predator-prey interactions between Isochrysis galbana and Oxyrrhis marina. I. Changes in particulate $\delta^{13} \mathrm{C}$. J Plankton Res 15:455-463

Flynn KJ, Mitra A (2016) Why plankton modelers should reconsider using rectangular hyperbolic (Michaelis-Menten, Monod) descriptions of predator-prey interactions. Front Mar Sci. https ://doi.org/10.3389/fmars.2016.00165

Fry B (2006) Stable isotope ecology. Springer Science + Business Media, LLC, New York, p 308

Gutiérrez-Rodríguez A, Décima M, Popp BN, Landry MR (2014) Isotopic invisibility of protozoan trophic steps in marine food webs. Limnol Oceanogr 59:1590-1598

Hoeinghaus DJ, Zeug SC (2008) Can stable isotope ratios provide for community-wide measures of trophic structure? Comment. Ecology 89:2353-2357

Hunt BPV, Allain V, Menkes C, Lorrain A, Graham B, Rodier M et al (2015) A coupled stable isotope-size spectrum approach to understanding pelagic food-web dynamics: a case study from the southwest sub-tropical Pacific. Deep Sea Res II 113:208-224

Hussey NE, MacNell MA, McMeans BC, Ollin JA, Dudley SFJ, Cliff $\mathrm{G}$ et al (2014) Rescaling the trophic structure of marine food webs. Ecol Lett 17:239-250

Jennings S, van der Molen J (2015) Trophic levels of marine consumers from nitrogen stable isotope analysis: estimation and uncertainty. ICES J Mar Sci 72:2289-2300

Jennings S, Maxwell TAD, Schratzberger M, Milligan SP (2008) Body-size dependent temporal variations in nitrogen stable isotope ratios in food webs. Mar Ecol Prog Ser 370:199-206

Kadoya T, Osada Y, Takimoto G (2012) IsoWeb: A Bayesian isotope mixing model for diet analysis of the whole food web. PLoS One 7:e41057. https://doi.org/10.1371/journal.pone.0041057

Layman CA, Arrington DA, Montaña CG, Post DM (2007) Can stable isotope ratios provide for community-wide measures of trophic structure? Ecology 88:42-48

Layman CA, Araujo MS, Boucek R, Hammerschlag-Peyer CM, Harrison E, Jud ZR et al (2012) Applying stable isotopes to examine food-web structure: an overview of analytical tools. Biol Rev $87: 545-562$

Mallela J, Harrod C (2008) $\delta^{13} \mathrm{C}$ and $\delta^{15} \mathrm{~N}$ reveal significant differences in the coastal foodwebs of the seas surrounding Trinidad and Tobago. Mar Ecol Prog Ser 368:41-51

Matthews B, Mazumder A (2005) Temporal variation in body composition $(\mathrm{C}: \mathrm{N})$ helps explain seasonal patterns of zooplankton $\delta^{13} \mathrm{C}$. Freshw Biol 50:502-515

Matthews B, Mazumder A (2007) Distinguishing trophic variation from seasonal and size-based isotopic $\left(\delta^{15} \mathrm{~N}\right)$ variation of zooplankton. Can J Fish Aquat Sci 64:74-83

Matthews B, Mazumder A (2008) Detecting trophic-level variation in consumer assemblages. Freshw Biol 53:1942-1953

McCarthy MD, Benner R, Lee C, Fogel ML (2007) Amino acid nitrogen isotopic fractionation patterns as indicators of heterotrophy in plankton, particulate, and dissolved organic matter. Geochim Cosmochim Acta 71:4727-4744
McCutchan JH, Lewis WMJ, Kendall C, McGrath CC (2003) Variation in trophic shift for stable isotope ratios of carbon, nitrogen, and sulfur. Oikos 102:378-390

Middelburg J (2014) Stable isotopes dissect aquatic food webs from the top to the bottom. Biogeosci 11:2357-2371. https://doi. org/10.5194/bg-11-2357-2014

Minagawa M, Wada E (1984) Stepwise enrichment of ${ }^{15} \mathrm{~N}$ along food chains: further evidence and the relation between $\delta^{15} \mathrm{~N}$ and animal age. Geochim Cosmochim Acta 48:1135-1140

Mitra A, Flynn KJ (2006) Accounting for variation in prey selectivity by zooplankton. Ecol Model 199:82-92

Mitra A, Flynn KJ (2007) Importance of interactions between food quality, quantity, and gut transit time on consumer feeding, growth, and trophic dynamics. Am Nat 169:632-646

Mompeán C, Bode A, Benítez-Barrios VM, Domínguez-Yanes JF, Escánez J, Fraile-Nuez E (2013) Spatial patterns of plankton biomass and stable isotopes reflect the influence of the nitrogen-fixer Trichodesmium along the subtropical North Atlantic. J Plankton Res 35:513-525

Moore JC, Berlow EL, Coleman DC, de Ruiter PC, Dong Q, Hastings A et al (2004) Detritus, trophic dynamics and biodiversity. Ecol Lett 7:584-600

Nilsen M, Pedersen T, Nilssen EM, Fredriksen S (2008) Trophic studies in a high-latitude fjord ecosystem-a comparison of stable isotope analyses $\left(\delta^{13} \mathrm{C}\right.$ and $\left.\delta^{15} \mathrm{~N}\right)$ and trophic-level estimates from a mass-balance model. Can J Fish Aquat Sci 65:2791-2806

Olive PJW, Pinnegar JK, Polunin NVC, Richards G, Welch R (2003) Isotope trophic-step fractionation: a dynamic equilibrium model. J Animal Ecol 72:608-617

Pantoja S, Repeta DJ, Sachs JP, Sigman DM (2002) Stable isotope constraints on the nitrogen cycle of the Mediterranean Sea water column. Deep Sea Res II 49:1609-1621

Parnell AC, Inger R, Bearhop S, Jackson AL (2010) Source partitioning using stable isotopes: coping with too much variation. PLoS One 5:e9672

Parnell AC, Phillips DL, Bearhop S, Semmens BX, Ward EJ, Moore JW, Jackson AL, Grey J, Kelly DJ, Inger R (2013) Bayesian stable isotope mixing models. Environmetrics 24:387-399

Pauly D, Christensen V, Dalsgaard J, Froese R, Torres F Jr (1998) Fishing down marine food webs. Science 279:860-863

Pecquerie L, Nisbet RM, Fablet R, Lorrain A, Kooijman SALM (2010) The impact of metabolism on stable isotope dynamics: a theoretical framework. Phil Trans R Soc B 365:3455-3468. https://doi. org/10.1098/rstb.2010.0097

Persson ME, Larsson P, Stenroth P (2007) Fractionation of $\delta^{15} \mathrm{~N}$ and $\delta^{13} \mathrm{C}$ for Atlantic salmon and its intestinal cestode Eubothrium crassum. J Fish Biol 71:441-452

Phillips DL, Inger R, Bearhop S, Jackson AL, Moore JW, Parnell AC, Semmens BX, Ward EJ (2014) Best practices for use of stable isotope mixing models in food-web studies. Can J Zoo 92:823-835. https://doi.org/10.1139/cjz-2014-0127

Pinnegar J, Campbell N, Polunin N (2001) Unusual stable isotope fractionation patterns observed for fish host-parasite trophic relationships. J Fish Biol 59:494-503

Post DM (2002) Using stable isotopes to estimate trophic position: models, methods, and assumptions. Ecology 83:703-718

Rau GH, Teyssie J-L, Rassoulzadegan F, Fowler SW $(1990){ }^{13} \mathrm{C} /{ }^{12} \mathrm{C}$ and ${ }^{15} \mathrm{~N} /{ }^{14} \mathrm{~N}$ variations among size-fractionated marine particles: implications for their origin and trophic relationships. Mar Ecol Prog Ser 59:33-38

Reddin CJ, O'Connor NE, Harrod C (2017) Living to the range limit: consumer isotopic variation increases with environmental stress. Peer J 4:e2034. https://doi.org/10.7717/peerj.2034

Reum JC, Jennings S, Hunsicker ME (2015) Implications of scaled $\delta^{15} \mathrm{~N}$ fractionation for community predator-prey body mass ratio estimates in size-structured food webs. J Anim Ecol 84:1618-1627 
Robinson D (2001) $\delta^{15} \mathrm{~N}$ as an integrator of the nitrogen cycle. Trends Ecol Evol 16:153-162

Rolff C (2000) Seasonal variation in $\delta^{13} \mathrm{C}$ and $\delta^{15} \mathrm{~N}$ of size-fractionated plankton at a coastal station in the northern Baltic proper. Mar Ecol Prog Ser 203:47-65

Van der Lingen CD, Miller TW (2011) Trophic dynamics of pelagic nekton in the southern Benguela current ecosystem: calibrating trophic models with stable isotope analysis. In: Omori K, Guo X, Yoshie N, Fujii N, Handoh IC, Isobe A, Tanabe S (eds) Interdisciplinary studies on environmental chemistry-marine environmental modeling and analysis, pp 85-94. TERRAPUB

Van der Zanden MJ, Rasmussen B (1999) Primary consumer $\delta^{13} \mathrm{C}$ and $\delta^{15} \mathrm{~N}$ and the trophic position of aquatic consumers. Ecology 80:1395-1404

Van der Zanden MJ, Rasmussen JB (2001) Variation in $\delta^{15} \mathrm{~N}$ and $\delta^{13} \mathrm{C}$ trophic fractionation: implications for aquatic food web studies. Limnol Oceanogr 46:2061-2066

Van Engeland T, De Kluijver A, Soetaert K, Meysman FJR, Middelburg JJ (2012) Isotope data improve the predictive capabilities of a marine biogeochemical model. Biogeosci Discuss 9:9453-9486. https://doi.org/10.5194/bgd-9-9453-2012

Van Oevelen D, Van den Meersche K, Meysman FJR, Soetaert K, Middelburg JJ, Vézina A (2010) Quantifying food web flows using linear inverse models. Ecosystems 13:32-45. https://doi.org/10.1007/ s10021-009-9297-6

Wada E, Hattori A (1991) Nitrogen in the sea: forms, abundances, and rate processes. CRC Press, Boca Raton, pp 1-208

Wolf N, Carleton SA, Martínez del Rio C (2009) Ten years of experimental animal isotopic ecology. Funct Ecol 23:17-26

Woodland RJ, Rodriguez MA, Magnan P, Glemet H, Cabana G (2012) Incorporating temporally dynamic baselines in isotopic mixing models. Ecology 93:131-144

Yeakel JD, Bhat U, Elliott Smith EA, Newsome SD (2016) Exploring the isotopic niche: isotopic variance, physiological incorporation, and the temporal dynamics of foraging. Front Ecol Evol 4:1. https ://doi.org/10.3389/fevo.2016.00001 